\title{
Computerized vs. Paper-Pencil Assessment of Cognitive Change following Acute Ischemic Stroke
}

\author{
Maude-Marie Gagnon ${ }^{1,2,3}$ and Robert Jr. Laforce ${ }^{1,2,3^{*}}$ \\ ${ }^{1}$ Département des Sciences Neurologiques, CHU de Québec-Université Laval, Québec, Canada \\ ${ }^{2}$ Clinique Interdisciplinaire de Mémoire, Département des Sciences Neurologiques, CHU de Québec-Université Laval, Québec, Canada \\ ${ }^{3}$ Faculty of Medicine, Laval University, Québec, Canada
}

"Corresponding author: Robert Jr. Laforce, Clinique Interdisciplinaire de Mémoire, CHU de Québec-Université Laval, 1401, 18e rue, Québec, Canada, Tel: 418-649-5980; E-mail: robert.laforce@fmed.ulaval.ca

Rec date: Nov 10, 2016; Acc date: Nov 26, 2016; Pub date: Nov 28, 2016

Copyright: (c) 2016 Laforce RJ, et al. This is an open-access article distributed under the terms of the Creative Commons Attribution License, which permits unrestricted use, distribution, and reproduction in any medium, provided the original author and source are credited.

\begin{abstract}
Importance: Cognitive impairment is common among patients with stroke and early recognition can optimize patient care.

Objective: To determine the validity of computerized cognitive testing in an adult population with acute ischemic stroke.

Design: Validation study comparing computerized vs paper-pencil assessments at two time points three months apart in a stroke unit.

Main outcome: Correlation analyses between computerized (using CogState Brief Battery) and paper-pencil testing (using the Montreal Cognitive Assessment) both at study entry and follow-up visits.

Results: We found moderate to strong significant correlations between the two instruments at study entry and follow-up sessions. Executive dysfunctions were the main cognitive changes. Test-retest correlations were strong.

Conclusion and Relevance: The CogState Brief Battery is a valid alternative for clinicians who wish to measure cognitive skills following acute ischemic stroke. Limitations of computerized testing are discussed.
\end{abstract}

Keywords: Computerized testing; Paper-pencil testing; Cognition; Stroke

\section{Background}

Cognitive impairment is common among patients with stroke, particularly in elderly population with comorbid conditions [1]. Indeed, two thirds of stroke survivors experience cognitive changes and many develop dementia [2]. These changes have a significant impact on long-term outcome and appear to be associated with a weaker rehabilitation potential as well as increased risk of death, disability [3], depression and a lower quality of life [4,5]. Early recognition and monitoring of cognitive changes in stroke is necessary to optimize patient care and this can guide therapy and rehabilitation strategies [6,7].

To this date, evidence shows that cognitive assessment using the Montreal Cognitive Assessment (MoCA) in cerebrovascular disease is valid, covering a wide range of functions including executive functions and memory [8-13] with the exception of processing speed. Education level has been consistently reported to impact the total score on MoCA [14]. The feasibility of the MoCA in ischemic stroke is significantly altered by aphasia. As such, computerized testing may provide an alternative to these limitations. For example, computerized testing allows measurement of attention, processing speed, working memory and visual learning. Furthermore, it offers test-retest sessions without practice effect [15-19].

Among the computerized assessment devices available, research has shown that the CogState Brief Battery is valid in different clinical populations including dementia [20,21] and concussion [22,23]. It has also been used for the assessment of attention in acute stroke and correlated with neuropsychological measures at 3 months [24].

To our knowledge, no study has yet compared the MoCA and the CogState in the acute phase and at 3-months post-stroke. Therefore, the goal of this research was to compare computerized vs paper-pencil cognitive assessment methods in patients with confirmed ischemic stroke both within the acute and later stages of an ischemic stroke. We hypothesized that computerized assessment results would be moderately correlated with the total score on MoCA in patients with ischemic stroke both at study entry and at 3-months follow-up.

\section{Methods}

This study was approved by the Ethics Review Board of the local research center (Centre Hospitalier Universitaire de Québec). All participants provided written informed consent. The authors were responsible for the study design and conduct. 
Page 2 of 5

\section{Participants}

Participants were men and women aged over 18 years old presenting with an acute ischemic stroke, confirmed by brain magnetic resonance imaging (MRI). Exclusion criteria were requirement of an interpreter, severe deficits in vision, hearing, language or motor impairment of the dominant arm preventing completion of the cognitive assessment, past history of dementia or severe intellectual disability, a diagnosis of acute delirium, an acute medical condition (such as myocardial infarction or sepsis), a living address off town and contra-indications to brain MRI (e. g. pacemaker)

\section{Design}

We conducted this validation study between July 2014 and October 2015 in the acute stroke unit of our tertiary neurological care center. The trial consisted of 3 phases: screening and recruitment, a first testing session within 2 weeks of the stroke and a follow-up testing session approximately 3 months post-stroke (Figure 1).

\section{Screening and Recruitment}

Medical files and brain MRI were screened for each participant (by one of the author). Demographic data (gender, age), history of disease, medication use, clinical presentation of stroke including language, vision, motor, sensory and cerebellar impairments as well as signs and symptoms suggestive of delirium (such as disorientation, psychomotor agitation or hallucinations) were collected (Table 1). Localisation and lateralisation of stroke as well as presence of at least one lobar cerebral microbleed (CMB) [25] and leukoaraiosis [26,27] were gathered (Table 2). All brain MRIs were reviewed (by one of the author) to confirm eligibility and to grade leukoaraiosis using Fazekas's scale. Susceptibility weighted imaging (SWI) sequences were also reviewed to validate presence and localisation of CMBs.

\section{Cognitive Measures}

Computerized testing was performed using the CogState Brief Battery (or Cognigram). For each task, instructions were provided on the computer screen, followed by a playing card presented face down in the center of the screen. After a short interval, the card turned face up and the participants were required to respond (with "yes" or "no") based on questions that varied for each task. It included 4 different tasks. The "Detection" task was a reaction time test of psychomotor function that required the participant to respond as quickly as possible when the central card was turned face up. The "Identification" task measured visual attention and required the participant to respond differently if the face up card was red or black. The "One card learning" task was a visual recognition learning task that assessed visual recognition memory and attention and required the participant to determine whether the face up card had appeared in the current task previously. The last task was the "One back" which assessed working memory and attention and required participants to determine whether the face up card was the same as the preceding card [16]. Performance measures were recorded for each trial on each task with speed in milliseconds and accuracy in percentage of correct and incorrect answers. Results were divided in 2 sections, each scored out of 200 points: "Attention and psychomotor function" which included the "Detection" and "Identification" tasks, and "Learning and working memory function" which included the "One card learning" and "One back" tasks. A score under 81 was considered abnormal, as standardized by CogState.

\begin{tabular}{|c|c|}
\hline Age (years): Mean (S.D), range & 67 (11.54), 44-87 \\
\hline Gender (\% male) & $17(68 \%)$ \\
\hline Level of education (years): Mean (S.D), range & 12 (2.96), 7-20 \\
\hline \multicolumn{2}{|l|}{ Medical history (\%) } \\
\hline Hypertension & $13(52 \%)$ \\
\hline Dyslipidemia & $12(48 \%)$ \\
\hline Diabetes & $8(32 \%)$ \\
\hline Previous stroke & $4(16 \%)$ \\
\hline Epilepsy & $2(8 \%)$ \\
\hline Coronary heart disease & $5(20 \%)$ \\
\hline Atrial fibrillation/flutter & $1(4 \%)$ \\
\hline Depression & $1(4 \%)$ \\
\hline \multicolumn{2}{|l|}{ Medication (\%) } \\
\hline Active use of psychotropic medications & $\begin{array}{l}5 \quad(20 \%): \quad \text { Zopiclone(2), } \\
\text { temazepam(1), trazodone } \\
\text { (1), quietiapine, mirtazapine } \\
\text { and lorazepam(1) }\end{array}$ \\
\hline \multicolumn{2}{|l|}{ Neurological sequelae (\%) } \\
\hline Visual impairment & $3(12 \%)$ \\
\hline Motor impairment (dominant hand) & $4(16 \%)$ \\
\hline Sensitive impairment (dominant hand) & $3(12 \%)$ \\
\hline Language impairment & $8(32 \%)$ \\
\hline Coordination impairment & $3(12 \%)$ \\
\hline No patent neurological deficit & $8(32 \%)$ \\
\hline
\end{tabular}

Table 1: Participants' characteristics $(\mathrm{n}=25)$.

Paper-pencil test consisted of the MoCA, a well-known written screening measure which includes various items (i.e. orientation, visuospatial ability, executive functions, language, memory, attention and abstraction) scored out of 30 [28]. A score under 26 on the MoCA is usually considered abnormal.

Administration of the MoCA and CogState Brief Battery was held in a quiet environment using standardized instructions. Participants were contacted by phone for scheduling of follow-up visit.

\section{Statistical Analysis}

Pearson's correlation coefficient tests were conducted both at initial and follow-up testing sessions using data from the MoCA total score (out of 30) and the CogState Brief Battery test scores (global score and sub-scores).

\section{Results}

Twenty-five patients were tested at study entry and 17 patients at 3 months follow-up (Figure 1). Mean age was 67 years old ( $\mathrm{SD}=11.54$; range 44-87). Hypertension, dyslipidemia and diabetes were the main comorbidities. The mean level of education was 12 years $(\mathrm{SD}=2.96$; 
Citation: Gagnon MM, Laforce JR (2016) Computerized vs. Paper-Pencil Assessment of Cognitive Change following Acute Ischemic Stroke. J

Page 3 of 5

range 7 to 20). A majority of patients presented significant neurological deficits $(17 / 25,68 \%)$ at study entry (motor or sensory impairments involving the dominant hand, persistent mild expressive aphasia in 6 patients, right quadranopsia or hemianopsia in 3 patients or incoordination (Table 1). Strokes more frequently involved the middle cerebral artery on the left side on brain MRI, leuroaraiosis was frequently described $(20 / 23,87 \%)$ whereas CMBs were rare $(4 / 23$, $17 \%)$. Cortical and subcortical atrophy was present in 15 patients (Table 2).

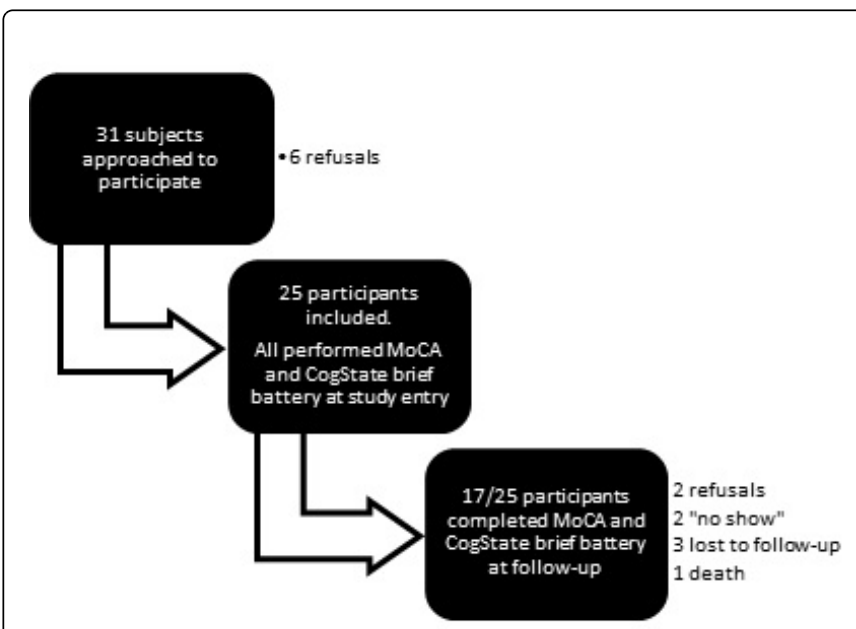

Figure 1: Study flowchart.

The mean MoCA score at study entry was $23 / 30$ ( $\mathrm{SD}=4.68$; range 12 to 30), and the mean scores for CogState Brief Battery were 91/200 for both parts (attention and psychomotor function: $\mathrm{SD}=15.42$, range 51 to 115 ; learning and working memory: $\mathrm{SD}=13.9$, range 61 to 114). At follow-up, the mean MoCA score was 25/30 ( $\mathrm{SD}=4.00$; range 13 to 30 ), and the mean scores for CogState Brief Battery were $96(\mathrm{SD}=13.35$; range 51 to 115) for "Attention and psychomotor function" and 97 ( $\mathrm{SD}=7.60$; range 61 to 114 ) for "Learning and working memory".

Correlational analyses between performances on the MoCA and CogState Brief Battery are shown in Table 3. Pearson correlation coefficients show moderate to strong correlations, with a significant moderate correlation between the global scores. Of note, correlation strength was similar after adjusting for age, gender and education level. Finally, there was a strong test-retest correlation $(0.76, \mathrm{p}=0.0004)$ for both computerized and paper-pencil measures.

\section{Discussion}

In this study, we aim to compare computerized vs paper-pencil cognitive assessment methods in patients with confirmed ischemic stroke, both within the acute and later stages of the process. We found a significant moderate correlation between the global scores on MoCA and CogState.

This was not influenced by age, gender or education level. Finally, both paper-pencil and computerized assessment techniques were associated with strong test-retest correlations.

At first glance, a computerized test which offers test-retest capabilities with no practice effect and is more feasible than many other cognitive assessments appeared interesting. However, we noted that some patients tended to lose interest in executing the task throughout testing likely as a result of repetitive patterns.

Other participants appeared anxious because of the computer-based format. Some patients clearly stated that the test was boring. On the other hand, the youngest participants appeared to appreciate the playful aspect of the computerized test, noticeably the playing cards and sound effects. In this population of patients with stroke, the same limitations in test execution were present for MoCA and CogState Brief Battery in terms of motor, sensory, visual and coordination deficits.

\begin{tabular}{|c|c|}
\hline Stroke localization (\%) & Column1 \\
\hline Anterior cerebral artery & $1(4 \%)$ \\
\hline Middle cerebral artery & $15(60 \%)$ \\
\hline Posterior cerebral artery & $1(4 \%)$ \\
\hline$\geq$ one large vessel & $3(12 \%)$ \\
\hline Infratentorial & $3(12 \%)$ \\
\hline Thalamic lacunar infarct & $2(8 \%)$ \\
\hline \multicolumn{2}{|l|}{ Stroke lateralization (\%) } \\
\hline Left & $13(52 \%)$ \\
\hline Right & $9(36 \%)$ \\
\hline Bilateral & $3(12 \%)$ \\
\hline \multicolumn{2}{|l|}{ Leukoaraiosis $(\%)^{*}$} \\
\hline Absence & $3(13 \%)$ \\
\hline Fazekas I & $16(70 \%)$ \\
\hline Fazekas II & $1(4 \%)$ \\
\hline Fazekas III & $3(13 \%)$ \\
\hline \multicolumn{2}{|c|}{ Cerebral microbleeds $(\%)^{*}$} \\
\hline Absence & $19(83 \%)$ \\
\hline Lobar & $2(9 \%)$ \\
\hline Alobar & $2(9 \%)$ \\
\hline \multicolumn{2}{|l|}{ Others (\%) } \\
\hline Presence of atrophy & $15 / 23(65 \%)$ \\
\hline Previous infarcts & $9 / 23(39 \%)$ \\
\hline Lacunar infarcts & $6 / 25(24 \%)$ \\
\hline
\end{tabular}

*All brain MRI included T2/FLAIR as well as SWI sequences except for 2 patients who had only a DWI sequence available. Therefore, the * indicates when the sample size was $n=23$.

Abbreviations: DWI: Diffusion-Weighted Imaging; MRI: Magnetic Resonance Imaging; FLAIR: Fluid-Attenuated Inversion Recovery; SWI: SusceptibilityWeighted Imaging.

Table 2: Brain imaging characteristics. 


\begin{tabular}{|l|l|l|l|l|}
\hline & $\begin{array}{l}\text { At study } \\
\text { entry } \\
(\mathbf{n}=\mathbf{2 5})\end{array}$ & $\mathbf{P}$ value & $\begin{array}{l}\text { At follow- } \\
\text { up (n=17) }\end{array}$ & P value \\
\hline Global scores & 0.40505 & $0.0446^{*}$ & 0.59966 & $0.0109^{* *}$ \\
\hline $\begin{array}{l}\text { Sub-scores(attention } \\
\text { and } \\
\text { functions) }\end{array}$ & 0.44078 & $0.0274^{*}$ & 0.42404 & 0.0898 \\
\hline $\begin{array}{l}\text { Sub-scores(learning } \\
\text { and working memory) }\end{array}$ & 0.29795 & 0.148 & 0.65124 & $0.0046^{* * *}$ \\
\hline${ }^{*} \mathrm{p}<0.05 ;{ }^{* *} \mathrm{p}<0.01$; and & ${ }^{* * *} \mathrm{p}<0.005$ & & & \\
\hline
\end{tabular}

Table 3: Correlation analyses between MoCA and CogState brief battery scores (Pearson's coefficients).

This study is flawed by several limitations. First, our gold standard remained a brief cognitive screening tool and ideally performances should have been compared to comprehensive neuropsychological tests. Another important limitation is the sample size, which is obviously very small. Moreover, there were many drop-outs, representing $32 \%$ of the total sample. Potential explanations include the study design, anxiety related to testing and lack of interest given the absence of a disease-modifying intervention. This is important to consider since it may reflect the difficulties faced by clinicians in performing cognitive assessments in this population. Our sample was composed of mildly disabled stroke patients and thus our findings lack generalisability. We excluded patients with severe acute stroke due to the fact that they could not complete the tasks. We found the MoCA to be equally flawed in patients with global aphasia, dominant hand paralysis or fluctuating levels of consciousness. The impact of language impairments was subjectively less pronounced with CogState but not totally absent. Participant indeed received written and oral instructions for every task. Administration of the computerized assessment was as time consuming as the MoCA and sometimes even longer. Finally, the CogState Brief Battery tended to categorize patients with abnormal MoCA as normal.

\section{Conclusion}

Altogether, we found moderate to strong significant correlations between computerized (CogState Brief Battery) and paper-pencil (MoCA) testing both at study entry and follow-up visits. Executive dysfunctions were the main cognitive changes. Test-retest correlations were strong. Computerized testing is a valid alternative for clinicians who wish to measure cognitive skills following acute ischemic stroke.

\section{Acknowledgements}

We thank all participants for their participation in the study. We are also grateful for the contribution of Audrey Paradis and Isabelle Sénéchal to scheduling and testing of participants.

\section{References}

1. Jacquin A, Binquet C, Rouaud O, Graule-Petot A, Daubail B, et al. (2014) Post-stroke cognitive impairment: High prevalence and determining factors in a cohort of mild stroke. J Alzheimers Dis 40: 1029-1038.

2. Jin YP, Di Legge S, Ostbye T, Feightner JW, Hachinski V (2006) The reciprocal risks of stroke and cognitive impairment in an elderly population. Alzheimers Dement 2: 171-178.
3. Patel MD, Coshall C, Rudd AG, Wolfe S (2002) Cognitive impairment after stroke: Clinical determinants and its associations with long-term stroke outcomes. J Am Geriatr Soc 50: 700-706.

4. Nys GM, Van Zandvoort MJ, De Kort PL, Van der Worp HB, Jansen BP, et al. (2005) The prognostic value of domain-specific cognitive abilities in acute first-ever stroke. Neurology 64: 821-827.

5. Nys GM, Van Zandvoort MJ, Van der Worp HB, De Haan EH, De Kort PL, et al. (2006) Early cognitive impairment predicts long-term depressive symptoms and quality of life after stroke. J Neurol Sci 247: 149-156.

6. Engstad RT, Engstad TT, Davanger S, Wyller TB (2013) Executive function deficits following stroke. Tidsskr Nor Laegeforen 133: 524-527.

7. Canadian Stroke Best Practices and Standards Working Group (2013) Section 7.2: Vascular cognitive impairment and dementia, In: Lindsay M, Gubitz G, Bayley M, Phillips S (eds) Canadian best practice recommendations for stroke care: Summary of stroke best practice recommendations p: 76-78.

8. Dong Y, Sharma VK, Chan BP, Venketasubramanian N, Teoh HL, et al. (2010) The Montreal Cognitive Assessment (MoCA) is superior to the Mini-Mental State Examination (MMSE) for the detection of vascular cognitive impairment after acute stroke. J Neurol Sci 299: 15-18.

9. Pendlebury ST, Cuthbertson FC, Welch SJ, Mehta Z, Rothwell PM (2010) Underestimation of cognitive impairment by mini-mental state examination versus the Montreal cognitive assessment in patients with transient ischemic attack and stroke: A population-based study. Stroke 41: 1290-1293.

10. Pendlebury ST, Markwick A, De Jager CA, Zamboni G, Wilcock GK, et al. (2012) Differences in cognitive profile between TIA, stroke and elderly memory research subjects: a comparison of the MMSE and MoCA. Cerebrovasc Dis 34: 48-54.

11. Koski L (2013) Validity and applications of the Montreal cognitive assessment for the assessment of vascular cognitive impairment. Cerebrovasc Dis 36: 6-18.

12. Cumming TB, Bernhardt J, Linden T (2011) The Montreal cognitive assessment: Short cognitive evaluation in a large stroke trial. Stroke 42: 2642-2644.

13. Godefroy O, Fickl A, Roussel M, Auribault C, Bugnicourt JM, et al. (2011) Is the Montreal cognitive assessment superior to the mini-mental state examination to detect post-stroke cognitive impairment? A study with neuropsychological evaluation. Stroke 42: 1712-1716.

14. You JS, Chen RZ, Zhang FM, Zhou ZY, Cai YF, et al. (2011) The Chinese (Cantonese) Montreal cognitive assessment in patients with subcortical ischemic vascular dementia. Dement Geriatr Cogn Dis Extra 1: 276-282.

15. Oliveira RS, Trezza BM, Busse AL, Jacob-Filho W (2014) Learning effect of computerized cognitive tests in older adults. Einstein (Sao Paulo) 12: 149-153.

16. Hammers D, Spurgeon E, Ryan K, Persad C, Heidebrink J, et al. (2011) Reliability of repeated cognitive assessment of dementia using a brief computerized battery. Am J Alzheimers Dis Other Demen 26: 326-333.

17. Collie A, Maruff P, Darby DG, McStephen M (2003) The effects of practice on the cognitive test performance of neurologically normal individuals assessed at brief test-retest intervals. J Int Neuropsychol Soc 9: 419-428.

18. Dingwall KM, Lewis MS, Maruff P, Cairney S (2009) Reliability of repeated cognitive testing in healthy indigenous Australian adolescents. Aust Psychol 44: 224-234.

19. Falleti MG, Maruff P, Collie A, Darby DG (2006) Practice effects associated with the repeated assessment of cognitive function using the CogState battery at 10-minute, one week and one month test-retest intervals. J Clin Exp Neuropsychol 28: 1095-1112.

20. Lim YY, Ellis KA, Harrington K, Ames D, Martins RN, et al. (2012) Use of the CogState brief battery in the assessment of Alzheimer's disease related cognitive impairment in the Australian Imaging, Biomarkers and Lifestyle (AIBL) study. J Clin Exp Neuropsychol 34: 345-358.

21. Hammers D, Spurgeon E, Ryan K, Persad C, Barbas N, et al. (2012) Validity of a brief computerized cognitive screening test in dementia. J Geriatr Psychiatry Neurol 25: 89-99. 
Citation: Gagnon MM, Laforce JR (2016) Computerized vs. Paper-Pencil Assessment of Cognitive Change following Acute Ischemic Stroke. J Neurol Disord 4: 317. doi:10.4172/2329-6895.1000317

Page 5 of 5

22. Makdissi M, Darby D, Maruff P, Ugoni A, Brukner P, et al. (2010) Natural history of concussion in sport: markers of severity and implications for management. Am J Sports Med 38: 464-471.

23. Maruff P, Thomas E, Cysique L, Brew B, Collie A, et al. (2009) Validity of the CogState brief battery: Relationship to standardized tests and sensitivity to cognitive impairment in mild traumatic brain injury, schizophrenia, and AIDS dementia complex. Arch Clin Neuropsychol 24: 165-178.

24. Cumming TB, Brodtmann A, Darby D, Bernhardt J (2012) Cutting a long story short: reaction times in acute stroke are associated with longer term cognitive outcomes. J Neurol Sci 322: 102-106.

25. Gregoire SM, Scheffler G, Jager HR, Yousry TA, Brown MM, et al. (2013) Strictly lobar microbleeds are associated with executive impairment in patients with ischemic stroke or transient ischemic attack. Stroke 44: 1267-1272.

26. Debette S, Markus HS (2010) The clinical importance of white matter hyperintensities on brain magnetic resonance imaging: systematic review and meta-analysis. BMJ 341.

27. Poggesi A, Pantoni L, Inzitari D, Fazekas F, Ferro J, et al. (2011) 2001-2011: A decade of the LADIS (Leukoaraiosis and disability) study: What have we learned about white matter changes and small-vessel disease? Cerebrovasc Dis 32: 577-588.

28. Vogel SJ, Banks SJ, Cummings JL, Miller JB (2015) Concordance of the Montreal cognitive assessment with standard neuropsychological measures. Alzheimers Dement 1: 289-294. 